\title{
Eye-contact and the recall of material involving competitive and noncompetitive associations
}

\author{
GORDON STANLEY and DONALD S. MARTIN, University \\ of New England, Armidale, Australia
}

On the assumption that eye-contact and avoidance is associated with anxiety increase and decrease, respectively, it was predicted that Ss would make less eye-contact with the $E$ when recalling material involving competing associations than with material involving noncompeting associations. Using an interview situation in which the $E$ asked for five Christian names beginning with the letter $T$ (competitive associations) and for recitation of the alphabet (noncompetitive associations) this prediction was confirmed. The presence of an $O$ looking, as distinct from the $O$ not looking, produced less eye-contact in the former than in the latter task.

Eye-contact, or the mutual glance between two people, is one of the most intimate and arousing of interpersonal actions (Tomkins, 1963). Recently there has been considerable experimental research which suggests that eye-contact reflects the degree of involvement between two persons (Argyle, 1967; Exline \& Winters, 1965). Other things being equal, the longer the periods of eye-contact, the greater the level of mutual involvement. However, as Argyle \& Kendon (1967) point out, in any situation there is a limit to the amount of mutual involvement that may be tolerated, and too much mutual looking may arouse anxiety. Exline, Gray \& Schuette (1965) reported that when Ss are asked embarrassing questions they engaged in less eye-contact than when asked innocuous questions about their recreational interests. Luborsky, Blinder \& Mackworth (1963) found a significant positive relationship between GSR responsivity and avoidant patterns of eye fixation when Ss were exposed to threatening stimuli. Their data suggest that visual avoidance is linked with the need to reduce arousal or anxiety. Thus, it appears that eye-contact is associated with an increase in anxiety and visual avoidance with anxiety reduction.

Exline \& Winters (1965) noted a tendency for Ss to look away when confronted with a cognitively difficult choice. Kendon (1967) reported that during passages of hesitant speech Ss look away, but during fluent speech they look back. According to Argyle \& Kendon $(1967$, p. 76) these findings "suggest that it is during the formulation of thought, when Ss might want to reduce information intake, that they look away." An alternative interpretation is that eye-contact is avoided for more complex material to reduce anxiety. In a number of studies Spence and his associates (summarized in Spence \& Spence, 1966) have demonstrated that high anxiety is facilitating in the situation of a well-learned or noncompetitive association, but debilitating in a competitive association situation. If eye-contact and avoidance is associated with anxiety increase and decrease, respectively, as suggested in the preceding paragraph, then it is likely that under conditions where $S$ s are required to recall material involving competing associations less eye-contact will occur than in situations involving recall of noncompeting associations.

In the present study it was predicted that a $S$ would make less eye-contact witl an E continually looking at him when asked to give five Christian names beginning with the letter $T$ (involving competitive associations ${ }^{2}$ ) than when asked to recite the alphabet (an overlearned task involving few competitive associations).
In an attempt to provide experimental manipulation of anxiety in the Ss, a second $E$ (the Q) was present and either looked at the $S$ throughout the interview or else looked continually at a notebook. It was assumed that when the $O$ was looking directly at the $\mathrm{S}$ more anxiety would be evoked than when he was just passively present. On the basis of this assumption it was predicted that under the conditions of this increased anxiety there would be even less eye-contact between $S$ and $E$ than in the O-passive condition.

\section{METHOD}

Subjects

The Ss were forty male students from an introductory psychology class at the University of New England. Ss were requested to attend the interview session which was purportedly being conducted to enable the $\mathrm{E}$ to gain practice in interviewing.

Apparatus

The experiment was conducted in a $15 \times 10 \mathrm{ft}$ academic study. Ss sat approximately $4 \mathrm{ft}$ in front of the $E$ who was seated behind an office desk $3 \times 4 \mathrm{ft}$. The $O$ sat on the same side of the desk as the $E$ and to his left, thus, subtending an horizontal angle of approximately $45 \mathrm{deg}$ to the S. A tape recorder and three-channel event-recorder were concealed in the rear of the room behind filing cabinets. Duration of speech and duration of eye-contact were recorded on Both graphed paper, No. 548. The microphone was located in clear view on the table. Using concealed push-button switches the $E$ recorded duration of eye-contact and the $O$ recorded who was speaking.

Experimental Design

A pilot run using 12 Ss was made to enable both $E$ and $O$ to perfect their roles. The question asked of the Ss in both the pilot study and main experiment formed part of a short interview. On any one occasion the noncompetitive question would be asked at the middle of the interview and the competitive question at the end or else the order would be reversed in a sequence which was counterbalanced within each group of Ss. The purpose of the short interview context was to eliminate any undesired orienting tendency which may occur at the commencement of an interpersonal interaction.

Procedure

The $S$ was met at the door of the interview room by the $E$. In the observer-looking situation the $O$ made a short comment about the weather to the $S$ and then looked at him for the remainder of the session. For the O-passive condition the $\mathrm{O}$ made no comment to the $S$, but sat looking down at a notebook. Each interview lasted approximately $3 \mathrm{~min}$ and at its conclusion the $S$ was thanked for helping the $E$ to get interviewing practice.

\section{RESULTS AND DISCUSSION}

The length of time that the $E$ or $S$ spoke and the duration of eye-contact was obtained from the output of the event-recorder. The percentage of eye-contact for the Ss' responses to each of the experimental questions was calculated and Table 1 shows the group means and standard deviations for each experimental condition. The raw score eye-contact means and standard deviations are in parentheses. An analysis of variance for a two-factor experiment with repeated measures was computed using these percentages as scores. The only significant $F$ comparison was for the main effect of Question Content $(F=11.53$, df $=1 / 40, p<.01)$. As the duration of responses to the competitive association question 
Table 1

Mean Percentage of Time Spent in Eye-Contact for Recall of Names Beginning with $T$ and the Alphabet when the Observer was Looking and not Looking

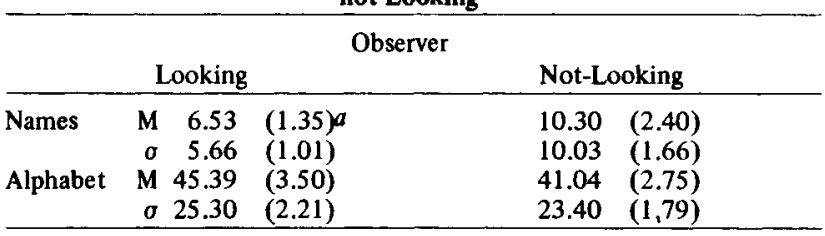

Note: $N=20$ per mean

a: Figures in parenthesis indicate absolute time in seconds.

(letter T) was consistently greater than for the noncompetitive association question (alphabet) a similar analysis of variance was computed using the raw scores for eye-contact. This was considered necessary to ensure that the percentage difference was not simply an artifact of response duration. The resulting analysis indicated again the significant Question-content factor $(F=11.69, \mathrm{df}=1 / 40, \mathrm{p}<.01)$, but also indicated a significant Observer-looking/Question-content interaction $(F=6.35, \mathrm{df}=1 / 40, \mathrm{p}<.01)$.

The foregoing analysis clearly supports the prediction that Ss exhibit less eye-contact when responding to a competing association question than to a noncompeting association question. However, the attempt at experimentally manipulating anxiety, by having the $\mathrm{O}$ looking, produced no significant main effect due to eye-contact. The significant Observerlooking/Question-content interaction which appeared in the second analysis did not occur significantly in the first analysis because of the different response-time for the two questions. Inspection of the means (Table 1) indicates that this interaction is primarily due to the O-looking condition producing a relatively much shorter eye-contact duration than the O-passive condition for the competing association question.

These two results support the analysis of eye-contact and avoidance in terms of anxiety and competing/noncompeting associations. It is interesting to note that this result occurs in a situation where the affective content of the questions is neutral and suggests that the previous research involving the relationship between affect and eye-contact should have been controlled for the cognitive complexity of the responses required.

\section{REFERENCES}

ARGYLE, M. The psychology of interpersonal behaviour. Baltimore: Penguin, 1967.

ARGYLE, M., \& KENDON, A. The experimental analysis of social performance. Advances in Experimental Social Psychology, 1967, 3 $55-98$

EXLINE, R., GRAY, D., \& SCHUETTE, D. Visual behaviour in a dyad as affected by interview content and sex of respondent. Journal of Personality \& Social Psychology, 1965, 3, 201-209.

EXLINE, R. V., \& WINTERS, L. C. Affective relations and mutual glances in dyads. In S. S. Tomkins and C. E. Izard (Eds.), Affect, cognition and personality. New York: Springer, 1965.

LUBORSKY, L., BLINDER, B., \& MACKWORTH, N. Eye fixation and recall of pictures as a function of GSR responsivity. Perceptual \& Motor Skills, 1963, 16, 469-483.

SPENCE, J. T., \& SPENCE, K. W. The motivational components of manifest anxiety: Drive and drive stimuli. In C. D. Spielberger (Ed.), Anxiety and behavior. New York: Academic Press, 1966.

TOMKINS, S. S. Affect, imagery, consciousness. Vol. II: The negative affects. New York: Springer, 1963. NOTES

1. The authors are grateful to J. K. Dua for useful comments on this study.

2. A small pilot study in which people were asked to give words beginning with the letter $\mathrm{T}$ evoked few Christian names as spontaneous responses. Hence, it was assumed that Christian names beginning with $T$ were lower in the response-hierarchy than other words beginning with $T$. 